\title{
Forensic acarology: an introduction
}

\author{
M. Alejandra Perotti · M. Lee Goff · Anne S. Baker · Bryan D. Turner • \\ Henk R. Braig
}

Received: 5 June 2009/ Accepted: 7 June 2009/Published online: 16 July 2009

(C) Springer Science+Business Media B.V. 2009

\begin{abstract}
Mites can be found in all imaginable terrestrial habitats, in freshwater, and in salt water. Mites can be found in our houses and furnishings, on our clothes, and even in the pores of our skin - almost every single person carries mites. Most of the time, we are unaware of them because they are small and easily overlooked, and-most of the timethey do not cause trouble. In fact, they may even proof useful, for instance in forensics. The first arthropod scavengers colonising a dead body will be flies with phoretic mites. The flies will complete their life cycle in and around the corpse, while the mites may feed on the immature stages of the flies. The mites will reproduce much faster than their carriers, offering themselves as valuable timeline markers. There are environments where insects are absent or rare or the environmental conditions impede their access to the corpse. Here, mites that are already present and mites that arrive walking, through air currents or material transfer become important. At the end of the ninetieth century, the work of Jean Pierre Mégnin became the starting point of forensic acarology. Mégnin documented his observations in 'La Faune des Cadavres' [The Fauna of Carcasses]. He was the first to list eight
\end{abstract}

\footnotetext{
M. Alejandra Perotti $(\bowtie)$

School of Biological Sciences, University of Reading, Whiteknights, Reading, Berkshire RG6 6AS, UK

e-mail: m.a.perotti@ reading.ac.uk

M. Lee Goff

Forensic Sciences Program, Chaminade University of Honolulu, 3140 Waialae Avenue, Honolulu, HI 96816-1578, USA
}

\section{A. S. Baker}

Department of Entomology, The Natural History Museum, Cromwell Road, London SW7 5BD, UK

B. D. Turner

Department of Forensic Science and Drug Monitoring, King's College London, 150 Stamford Street, London SE1 9NH, UK

H. R. Braig

Bangor University, School of Biological Sciences, Deiniol Road, Bangor, Wales LL57 2UW, UK 
distinct waves of arthropods colonising human carcasses. The first wave included flies and mites, the sixth wave was composed of mites exclusively. The scope of forensic acarology goes further than mites as indicators of time of death. Mites are micro-habitat specific and might provide evidential data on movement or relocation of bodies, or locating a suspect at the scene of a crime. Because of their high diversity, wide occurrence, and abundance, mites may be of great value in the analysis of trace evidence.

Keywords Carcass · Forensics - Animal decomposition · Trace evidence · Post mortem interval

\section{Introduction}

Mites are everywhere! Mites can be found in all imaginable terrestrial habitats, in freshwater, in salt water; mites can be found in our houses, on the curtains, in and on our mattresses, on our clothes, and even in the pores of our skin. Many mites feed on microorganisms associated with decay and they, in turn, form the diet of predatory species. Others are parasites and commensals of plants, vertebrates and invertebrates, with varying degrees of host specificity. Most of the time, we are unaware of them because they are small and easily overlooked.

Mites have colonised as many habitats as insects and have better exploited modern living and working conditions, especially those in temperate climates and developed countries. The storage of food in refrigerators and the common use of synthetic fabrics and carpets have successfully limited the number and diversity of insects to a point where the arrival of a single fly can cause surprise and annoyance. Our homes and means of transport contain a surprising variety of species, mostly unnoticed by us, and surveys of indoor environments have demonstrated the range of microhabitats exploited by them. Extensive and detailed work on so-called dust mites has clearly established that mite species on our bed linen are very different from the mite species below our beds. Mites on our clothes are different from the mites on our skin and the mites associated with the living room couch. Moving from habitat to habitat and room to room, mites inhabit an incredible variety of microhabitats, exhibiting considerable specialisation and spatial resolution in diversity (Frost et al. 2009).

Compared to the routine use of insect evidence, mites, despite their ubiquity and diversity, hardly feature in the field of forensics. In addition to problems associated with their small size, their use is inhibited by the difficulty of identification and lack of comprehensive knowledge about, for example, distribution, length of life cycle in natural habitats and, in the case of those transported by other invertebrates, the range of carrier species.

In this article we present an overview of mites in forensics and ask what capacity they have to make a greater contribution to modern investigations. The first mite associations observed in criminal cases were with human corpses. From investigations of mites on decomposing human and animal remains, there is a progression to mites as potential indicators of crime and as trace evidence to link objects or persons to a particular habitat at a certain point in time. Modern forensic entomology has now a record of at least 150 years of case studies and research. Forensic acarology should make good use of this and rapidly develop into a valuable alternate input into forensic analysis (Turner 2009). 


\section{Recognition and the first case}

In recent years the importance of insects for forensic investigations has first been shown to the general public through popular science books such as 'Maggots, murder, and men: Memories and reflections of a forensic entomologist' (Erzinçlioglu 2000). 'A fly for the prosecution: How insect evidence helps solve crimes' (Goff 2001), 'Corpse: Nature, forensics and the struggle to pinpoint time of death' (Sachs 2001), 'Death's acre: Inside the legendary 'Body Farm', (Bass and Jefferson 2003), 'Murderous methods: Using forensic science to solve lethal crimes' (Benecke 2005), and fictional novels like 'The body farm' (Cornwell 1994), 'Blow fly' (Cornwell 2003), 'Shoofly pie: A Bug Man novel' (Downs 2003), 'Chop Shop' (Downs 2004), 'First the dead: A Bug Man novel' (Downs 2008), to name a few. An even stronger impact comes from television shows as 'Forensic Files', 'Dirty Jobs' or 'CSI: Crime Scene Investigation', the latter one has been advised and inspired on some episodes by an acarologist who works on chigger mites.

However, the modern science of employing arthropods in forensic investigations started in the early 1800s in France, Germany, Italy and Spain (Benecke 2001; Amendt et al. 2004; Klotzbach et al. 2004). Only the second criminal case in France's history that used arthropods for estimating a post mortem interval of a corpse employed mites. The corpse was that of a newborn baby girl found on waste ground of the rue Rochebrune in Paris, in January of 1878 (Brouardel 1879, 1895; Benecke 2001). It was covered in some kind of linen cloth soaked with moisture and rotten at the points that made contact with the soil. The body itself was completely mummified and sounded like cardboard according to the pathologist, Brouardel, performing the autopsy. The first case of using entomological evidence for the estimation of a post mortem interval, thirty years earlier (1848), was also a case of a mummified newborn baby (Bergeret 1855). The corpse in Brouardel's case had caterpillars of the grease and fungus moth genus Aglossa (Pyralidae, Lepidoptera), which were already known to feed on fatty substances, in this case possibly on the precursors of grave wax or adipocere of the mummy. Aglossa pinguinalis and A. caprealis have been found near and on carcasses. No attempt was made to estimate the age of the moth larvae. The moths might have arrived early on the carcass because it takes several months before pyralid larvae start constructing characteristic silk tubes around themselves. However, there was no mention in the report of any such structures. Another possibility might be that the Aglossa species was rather recently attracted by the damp linen and so was a late arrival.

Also, the corpse was covered on the outside by a brownish layer, some $2 \mathrm{~mm}$ thick, composed exclusively of mite carcasses, exuviae and feces. Live mites were found in the interior of the child's cranium. All mites belonged to a single species, the seed mite Tyroglyphus longior, now known as Tyrophagus longior (Acaridae, Astigmata), a species that is particularly active at lower ambient temperatures. It was known to feed on the fatty acids and soapy substances containing ammonia that form on carcasses during dry decomposition (Brouardel 1879). Other insects or arthropods, including Dermestes beetles (Dermestidae, Coleoptera), were noticeably absent. It was estimated that the corpse had a surface area of $3,000 \mathrm{~cm}^{2}$ including the internal surface of the cranial cavity. Four mites, exuviae or eggs were counted per $\mathrm{mm}^{3}$, resulting in a total of $2,400,000$, mainly dead, mites on and in the entire corpse. Based on the then already published life histories of $T$. longior and T. mycophagus it was assumed that a few hypopial nymphs initially had arrived phoretically on the corpse. It was suggested that the mite arrived on flies, beetles or myriapods as transport hosts. Aglossa as a possible vector of the mite was not discussed, perhaps because moths and butterflies were not well known at that time as phoretic hosts of 
mites. Aglossa costiferalis, for example, is now known as a carrier for the mite Blattisocius tarsalis (Ascidae, Mesostigmata) (Treat 1975). However, there are some acarological problems. The species $T$. longior has lost the deutonymphal life stage at which the phoretic hypopi that attach to carrier hosts develop. Therefore, either $T$. longior arrived at the corpse by a different route or the mite species on the corpse was not $T$. longior. Details of this question are discussed in the article dedicated to this particular case, where the mite evidence is also re-analysed (Perotti 2009).

For the calculation of the post mortem interval of the mummified corpse it was assumed that every female of $T$. longior would give birth to 10 daughters and 5 sons, which would mature within 15 days. The original calculation was simply based on the following table:

\begin{tabular}{llrr}
\hline 1st generation after & 15 days & 10 Females & 5 Males \\
\hline 2nd & 30 & 100 & 50 \\
3rd & 45 & 1,000 & 500 \\
4th & 60 & 10,000 & 5,000 \\
5th & 75 & 100,000 & 50,000 \\
6th & 90 & $1,000,000$ & 500,000 \\
\hline
\end{tabular}

The minimum time necessary to achieve $1,500,000$ mites is 3 months. Taking into account other factors, Brouardel estimated that the corpse was exposed to the air for 6-8 months. Brouardel, a professor of legal medicine, had asked for help with the mite identification from Mégnin, a veterinary surgeon in the French army who recently had become interested in mites. Mégnin continued later on to write, among other things, textbooks on parasitic mites and the fauna of corpses (Mégnin 1892, 1894). It took more than a hundred years before mites were recognised and used again to estimate a post mortem interval in a homicide case. As for many years in the case of insects, so many forensic scientists have been unaware of a potentially rich source of information for their investigations in the form of mites that has been right in front of their eyes.

\section{Carcasses and time of death}

During the first $72 \mathrm{~h}$ after death, medical parameters of the carcass are of most use to estimate the post mortem interval. Occasionally, a few eyelashes are plucked and examined microscopically for the presence of mites. The follicle mite, Demodex folliculorum (Demodicidae [Demodecidae], Prostigmata), is primarily found in the hair follicles of the eyelashes and eyebrows. If the mite is present, the chances of which increase with the age of the person, estimation of the time interval from death may be based on whether or not the mites are still alive. A second species, D. brevis, lives in the sebaceous glands of the follicles. Desch (2009) discusses the role of these mites in forensic studies.

The next stage in the decomposition of a corpse is most often covered by a complete cycle of blow flies (Calliphoridae) or flesh flies (Sarcophagidae). Life history data for the most common blow and flesh flies have been reasonably well established and can provide in many cases accurate estimations of a post mortem interval. After that, the successional 
colonisation of the remains by other insect groups provides a more coarse framework for the estimation of time. Lee Goff reviews the individual stages of decomposition of a human corpse in this issue (Goff 2009). Experimental studies on human decomposition are rare and so far have been limited to the University of Tennessee Forensic Anthropology Facility, frequently called the 'body farm', near Knoxville, Tennessee (Bass and Jefferson 2003). A new facility was opened in 2006 at the Western Carolina Human Identification Laboratory of the Western Carolina University in Cullowhee, North Carolina, while the Department of Anthropology of the Texas State University-San Marcos is currently considering a Forensic Anthropology Research Facility for Texas. Experiments on animal decomposition are slightly more numerous. Mites have been described on human and animal carcasses deposited in terrestrial habitats (Braig and Perotti 2009). A dominant and important group of mites associated with human and animal decomposition is the Astigmata (OConnor 2009). Mites can arrive in four principal ways at these carcasses, i.e., by walking, air currents, material transfer and biological transport as a phoront on another animal. The case of the mummified newborn baby described earlier may or may not have involved a phoretic mite species. Certain mite species have only been found attached to a specific species of insect for transportation, while others are phoretic on a wider range of taxa. Each different insect species might bring its own specific mite species to the dead body. The biology of phoresy of mites is important for the understanding of the behaviour and ecology of many mites associated with carcasses (Perotti and Braig 2009; Perotti et al. 2009).

Circumstances and stages of decomposition where mites might contribute valuable information to forensic investigations are manifold. Butyric fermentation and advanced decay will attract mites in such numbers that they become visible to the naked eye. However, they are often mistaken for mould, which is present at that time as well, or for fine sawdust, as has been emphasised by Haskell et al. (1997).

The most obvious contribution is to the area of long post mortem intervals, especially the dating of the later stages of dry decay or decomposition. During the drying stage, empty puparia are often employed for the identification of past insect species. These puparia might have many associated live mites (Haskell et al. 1997). These mites are not identified or used. Later, hardened exoskeletons of many beetles persist. These structures are often broken to a point where they become difficult to recognise. Dead mites are preserved as well but because of their much smaller size, they suffer considerably less damage than insects. Dead mites of many species can relatively easily be rehydrated, which will greatly facilitate their identification and thus potentially shed light on their manner and time of arrival. The well-sclerotized exoskeleton of members of the Oribatida, for example, persists for a long time after their death. Some species, e.g., of Rostrozetes (Haplozetidae), feed on dry skin in the later stages of decomposition.

Corpses deprived of blow or flesh flies, either through the absence of fly activity or increasingly through various forms of concealment of the body, constitute the biggest challenge for forensic entomology. Invasion of indoor corpses relies on the activity of outdoor flies, either blow or flesh flies. In many temperate countries, these flies are not available for colonisation for some months of the year. Remains are more and more being sheltered in a house or vehicle, or purposely concealed in a careful way restricting access by blow and flesh flies. In these cases, beetles will be one of the first major insect groups that might invade the corpse. Post mortem estimates based on beetle data are hampered by the fact that the number of instars, which is constant for fly species, varies for many beetle species depending on the stress environmental and nutritional conditions exert on the local population. The succession of mites might help resolve some of these problems. Recent forensic studies focus on tiny carrion-breeding scuttle flies (Phoridae) that still might get 
access where blow flies and other Calyptrata are successfully excluded from the corpse (Disney and Manlove 2005; Disney 2006). These scuttle flies might become even more valuable because they transport phoretic mites to the body to start a new succession of mite species (Fain and Greenwood 1991; Fain 1998a, b). Some of these species, for example Macrocheles disneyi (Macrochelidae, Mesostigma), have to date only been found on a phorid carrier (Fain and Greenwood 1991). In the absence of insects, decay is primarily a function of bacteria action. These are likely to attract a variety of bacteriophagous mites, which, in turn, will attract a variety of predatory mites. A complex food web of mites feeding on bacteria, algae, fungi, insect eggs and other mites will establish, starting a succession of different mite species. These mites are almost always overlooked, either because of their size, the lack of specific knowledge about them or they are not picked up using current forensic methods. Mite succession potentially constitutes a completely untapped resource for forensic purposes and could achieve greater resolution data in terms of time since death. Because mites have much shorter generation times and life spans than insects, the succession of mites might be faster than the succession of insects. This opens up the possibility of a higher resolution in estimating the post mortem interval.

The potential value of phoretic mites in terms of increased time resolution might be illustrated by the following factors. Many phoretic mite species are haplodiploid and the phoretic stage is female. In some species, the first generation after transport will be entirely male. Just by observing the sex ratio of a particular population, one might estimate a minimum time for that species on the body.

Mites have a greater diversity than insects in certain circumstances where carcasses come to rest. For example, few taxa of insects live in salt water (although they may be present in large numbers), whereas many aquatic mite species are present there. However, the question of whether or not mites contribute to the decomposition of submerged carcasses has never been addressed (Proctor 2009).

\section{Forensic indicators}

A wide range of biological material has been used to indicate circumstances surrounding actual or suspected criminal activity. Insects have been used as forensic indicators for as long as urban, medical and veterinary entomologists have investigated food spoilage, myiasis, stored product pests, and structural pests like termites or death watch beetles; the majority of cases being on the civil and litigation side, rather than on the criminal side. Davis (1928) suggested the presence of greenbottle flies of the genus Lucilia might indicate the approaching death of humans. Diatoms have been used to indicate whether a drowning victim might have been conscious, unconscious, already dead or might have experienced a sudden death when entering the water.

The use of insects like the false stable fly, Muscina stabulans (Muscidae, Diptera), and the lesser house fly, Fannia canicularis (Fanniidae, Diptera), in cases of child and elder neglect has brought insects and criminal forensic investigations more to the forefront of attention (Benecke and Lessig 2001; Benecke et al. 2004). Forensic investigations associated with animals in general, but focusing on animal cruelty investigations and with wildlife in particular, are becoming more prominent (Sinclair et al. 2006; Cooper and Cooper 2007; Merck 2007).

Mites have been used in archaeology as indicators of habitat type, human social and economic activities, and animal husbandry (Schelvis 1990, 1994; Ervynck 1999; Nielsen et al. 2000; Chepstow-Lusty et al. 2007). As with modern forensics, however, they have 
been much less used in analyses than have insects. Fossil soil mites are also used as indicators to reconstruct habitats (Solhoy and Solhoy 2000; Coetzee and Brink 2003). The abundance of soil mites and a respectable number of existing soil acarologists could contribute hugely to forensic soil analyses. In more damp soil near fresh water and in leaf litter, testate amoebae (rhizopods, thecamoebians), terrestrial species with a hard shell that remains intact, might provide additional forensic information (Gunn 2006).

On outdoor corpses, different blow fly species dominate in urban and in rural environments (Hwang and Turner 2005). Species composition also changes with latitude and season. Recent carrion succession studies, on open-air pigs in a European urban habitat, showed that two species considered to be biogeographic indicators for rural and shaded locations were dominant in the inner city. Also, a non-indigenous species, previously associated exclusively with southern tropical and subtropical habitats, has exhibited a range expansion (Grassberger and Frank 2004). The local and spatial resolution of blow flies for common crime locations might, therefore, become coarser in the years to come (Amendt et al. 2009). Mites in outside habitats are abundant and very diverse. The range of species of phoretic mites on insects that visit carcasses has not yet been appreciated. Determining the mite fauna associated with carcasses has the potential to significantly increase the amount of location-specific information and, hence, contribute immensely to questions of possible movements of bodies between less disparate habitats. Several groups of insects are known to visit carcasses at specific stages of decay but do not leave behind any recordable evidence that could be utilised. Butterflies and moths, for example, are well known to feed off the seepage from carcasses but are of no value for forensic evaluations. Yet, these insects might again contribute specific phoretic mites to the body and alter the succession of mite species.

\section{Trace evidence}

Forensic botany, particularly palynology, is a well-established discipline that primarily provides information on trace evidence, ecological information related to origin and identity, i.e., that which is present as a result of contact between people or objects and their surroundings. By determining the identity of pollen found, ecological information relating to origin can be given. Mites could also be used in such a way. Like pollen, they are small and light, and so have the capacity to be picked up unknowingly by humans, e.g., on their clothing or hair, and on other objects. Fibres of any kind have gained great importance as trace evidence in forensic investigations. Most mites are considerably smaller than fibres and may be more abundant under certain condition. These mites have DNA, whereas fibres do not, therefore they have the potential to provide complementary evidence. Some mites can even bite and leave forensically important information on a suspect (Turner 2009).

Insects have generally become less diverse in modern living quarters. Detailed studies of the causes of human allergies clearly show that this is not the case for mites. Often lumped together under the common name of 'dust mites', the omnipresence and diversity of these mites escapes the non-acarologist. A first record of the mites of stored food and houses in the UK has been assembled by Hughes (1976). Later, Van Bronswijk (1981) listed 147 mite species that had been recorded from house dust around the world. The taxa included species regarded to be visitors, e.g., plant and soil mites brought in with pot plants or on the shoes of people or the feet of pets, and disembarked parasites of pets and other animals. The permanent inhabitants comprised members of the Oribatida, Prostigmata, Mesostigmata and Astigmata; the greatest number of individuals and species belonging to the latter. Since 
1981, many more detailed descriptions of the mites in domestic situations have been published, for example, those on bed linen, curtains, window sills, clothes, pets and in other indoor microhabitats (Colloff and Hopkin 1986; Horak et al. 1996; Arlian 2002; Frost et al. 2009). The work has clearly established that mite species on our bed linen are very different from the mite species below our beds. Mites on our clothes and the living room couch are different from the mites on our skin. Moving from habitat to habitat and room to room, mites inhabit an incredible variety of microhabitats, and exhibit specialisation and spatial resolution in diversity (Frost et al. 2009). Also, almost every detritivorous mite will attract its own predatory mite species, which in part explains the high diversity of the indoor mite fauna (Frost et al. 2009) .

House dust dwelling astigmatids include species that are also present in stored foods, e.g., members of the families Acaridae and Glycyphagidae (Hughes 1976), but the extensive literature on the fauna shows that the most abundant species belong to the family Pyroglyphidae, which feed on the skin flakes and other dander found in our homes. In a global survey, Dermatophagoides pteronyssinus, D. farinae and Euroglyphus maynei accounted for up to $90 \%$ of the house dust fauna (Blythe et al. 1974; Crowther et al. 2000).

New houses and homes might be colonised via the movement of mite-infested furniture or soft furnishings, the use of another arthropod for transport (phoresy), air currents or simply brought in by humans, e.g., on clothing, and their pets (Bischoff and Kniest 1998; Warner et al. 1999). House dust mites do not like to establish populations in new houses until humans are present (Warner et al. 1999). This is a very important point. The indoor acarofauna depends on the people living or working in these houses and homes. These indoor environments are important locations for forensic investigations, but this richness of mite biodiversity has not been exploited by forensic investigators. In this issue, Solarz (2009) focuses on the mites in a variety of indoor habitats.

Mites originating from outdoor habitats can also be useful trace evidence and give accurate evidence about movements or transportation of a body. For example, eggs and other immature stages of phytophagous mites can survive several days attached to decaying leaves associated with a body, while species such as Cenopalpus pulcher, which in Britain has only been found on unsprayed apple trees (Evans et al. 1961), have very restricted distributions. Plant parasitic mites show a much higher degree of diversity, polymorphism and spatial resolution than the host plant itself.

Mites also occur in artificial aquatic situations and contamination of corpses and other evidence of forensic interest. Trimalaconothrus maniculatus and T. aquatilis (Malaconothridae, Oribatida) and Histiostoma ocellatum (Histiostomatidae, Astigmata) have only been found in swimming pools or aquaria and complete their entire life cycle in water (Fain et al. 1986). Another oribatid, Trhypochthoniellus crassus (=Hydronothrus aquariorum and H. crispus, according to Seniczak et al. 1998) (Trhypochthoniidae), occurs in natural freshwater habitats, but also in swimming pools and aquaria. In a survey of 36 indoor swimming pools in Japan, 53\% were positive for mites, whereas no mites were found in the four outdoor pools examined (Kazumi et al. 1992). Trhypochthoniellus crassus and T. maniculatus were found in a restricted geographical area, while H. ocellatum occurred widely throughout the country. Individual pools were mainly colonised by a single species.

\section{The next step}

To realise the potential of mites and forensic acarology, it is necessary to produce the data that clearly demonstrate how mites can contribute to investigations. At the same time, it 
will be important to raise the awareness of forensic scientists and investigators. However, ultimately for forensic acarology to take off, it will require that the forensic investigators collaborate with acarologists in a more open interaction. Even if the agencies and companies in charge of forensic investigations would have the resources to hire acarologists, there might not be enough acarologists left to fill the positions. Therefore, a following priority is to provide more user-friendly identification aids, such as picture-based keys, covering the diversity of mites (Baker 1999; Walter and Proctor 2001).

The ubiquity of mites means that there are few situations in which people and objects associated with crime will not be exposed to them. But, as well as being a potentially rich source of evidence, this has a disadvantage. If specimens found on a suspect or victim belong to a species that occurs in virtually every household, little information can be gained. DNA of the trace mites might provide a molecular fingerprint of the particular mite colony, thus immensely increasing the information content and resolution of mites as evidence. Since forensic laboratories are currently laid out to process molecular evidence, the future success of forensic acarology might depend on the adoption of molecular tools in the identification and characterisation of mites.

Acknowledgments A. S. B., B. D. T., H. R. B. and M. A. P. wish to thank the Leverhulme Trust for supporting this work.

\section{References}

Amendt J, Krettek R, Zehner R (2004) Forensic entomology. Naturwissenschaften 91:51-65

Amendt J, Zehner R, Johnson DG et al (2009) Future trends in forensic entomology. In: Amendt J, Goff ML, Campobasso CP et al (eds) Current concepts in forensic entomology. Springer, Dordrecht

Arlian LG (2002) Arthropod allergens and human health. Annu Rev Entomol 47:395-433

Baker AS (1999) Mites and ticks of domestic animals, an identification guide and information source. Natural History Museum, London

Bass B, Jefferson J (2003) Death's acre: inside the legendary "body farm”. G. P. Putnam's Sons, New York Benecke M (2001) A brief history of forensic entomology. Forensic Sci Int 120:2-14

Benecke M (2005) Murderous methods: using forensic science to solve lethal crimes. Columbia University Press, New York

Benecke M, Lessig R (2001) Child neglect and forensic entomology. Forensic Sci Int 120:155-159

Benecke M, Josephi E, Zweihoff R (2004) Neglect of the elderly: forensic entomology cases and considerations. Forensic Sci Int 146:S195-S199

Bergeret M (1855) Infanticide. Momification naturelle du cadavre. Découverte du cadavre d'un enfant nouveau-né dans une cheminée où il s'était momifié. Détermination de l'époque de la naissance par la présence de nymphes et de larves d'insectes dans le cadavre et par l'étude de leurs métamorphoses [Infanticide. Natural mummification of the corpse. A corpse of a new-born child discovered in a chimney where it had been mummified. Determination of the time of the birth by the presence of nymphs and larvae of insects in the corpse and by the study of their metamorphoses]. Ann Hyg Publ Méd Lég (série 2) 4:442-452

Bischoff ERC, Kniest FM (1998) Differences in the migration behaviour of two most widespread species of house dust mites (HDM). J Allergy Clin Immunol 101:S28

Blythe ME, Williams JD, Smith JM (1974) Distribution of pyroglyphid mites in Birmingham with particular refrence to Euroglyphus maynei. Clin Allergy 4:25-33

Braig HR, Perotti MA (2009) Carcasses and mites. Exp Appl Acarol 49. doi:10.1007/s10493-009-9287-6

Brouardel P (1879) De la détermination de l'époque de la naissance et de la mort d'un nouveau-née, faite à l'aide de la présence des acares et des chenilles d'aglosses dans cadavre momifié [Determination of the time of birth and of death of a new-born child, made using the presence of mites and Aglossa caterpillars on the mummified corpse]. Ann Hyg Publ Méd Lég (série 3) 2:153-158

Brouardel P (1895) La mort et la mort subite [Death and Sudden Death]. J. B. Baillière et fils, Paris

Chepstow-Lusty AJ, Frogley MR, Bauer BS et al (2007) Evaluating socio-economic change in the Andes using oribatid mite abundances as indicators of domestic animal densities. J Archaeol Sci 34:1178-1186 
Coetzee L, Brink JS (2003) Fossil oribatid mites (Acari, Oribatida) from the Florisbad Quaternary deposits, South Africa. Quat Res 59:246-254

Colloff MJ, Hopkin SP (1986) The ecology, morphology and behavior of Bakerdania elliptica (Acari, Prostigmata, Pygmephoridae), a mite associated with terrestrial isopods. J Zool A 208:109-124

Cooper J, Cooper ME (2007) Introduction to veterinary and comparative forensic medicine. Blackwell, Malden

Cornwell PD (1994) The body farm. Little, Brown, London

Cornwell PD (2003) Blow fly. Little, Brown, London

Crowther D, Horwood J, Baker N et al (2000) House dust mites and the built environment: a literature review. University College London, London

Davis WT (1928) Lucilia flies anticipating death. Bull Brooklyn Entomol Soc 23:118

Desch CE (2009) Human hair follicle mites and forensic acarology. Exp Appl Acarol 49. doi: 10.1007/s10493-009-9272-0

Disney RHL (2006) Duration of development of some Phoridae (Dipt.) of forensic significance. Entomol Mon Mag 142:129-138

Disney RHL, Manlove JD (2005) First occurrences of the phorid, Megaselia abdita, in forensic cases in Britain. Med Vet Entomol 19:489-491

Downs T (2003) Shoofly pie: a bug man novel. Howard Publishing, West Monroe

Downs T (2004) Chop shop. Howard Publishing, West Monroe

Downs T (2008) First the dead: a bug man novel. Thomas Nelson Publishers, Nashville

Ervynck A (1999) Possibilities and limitations of the use of archaeozoological data in biogeographical analysis: a review with examples from the Benelux region. Belg J Zool 129:125-137

Erzinçlioglu YZ (2000) Maggots, murder, and men: memories and reflections of a forensic entomologist. Harley Books, Colchester

Evans GO, Sheals JG, MacFarlane D (1961) The terrestrial acari of the British Isles: and introduction to their morphology. Biology and Classification, Dorking

Fain A (1998a) New mites (Acari) phoretic on Phoridae and Ephydridae (Diptera) from Thailand. Bull Inst R Sci Nat Belg Entomol 68:53-61

Fain A (1998b) Description of mites (Acari) phoretic on Phoridae (Insecta: Diptera) with description of four new species of the genus Uroseius Berlese (Parasitiformes, Uropodina, Polyaspididae). Int J Acarol $24: 213-220$

Fain A, Greenwood MT (1991) Notes on a small collection of mites Acari phoretic on Diptera mainly Phoridae from the British Isles. Bull Inst R Sci Nat Belg Entomol 61:193-197

Fain A, Lambrechts L, Belpaire C (1986) Acariasis, a new parasitic disease of aquarium fishes. Trop Fish Hobbyist 34:76

Frost CL, Braig HR, Amendt J et al (2009) Indoor arthropods of forensic importance. In: Amendt J, Goff ML, Campobasso CP et al (eds) Current concepts in forensic entomology. Springer, Dordrecht

Goff ML (2001) A fly for the prosecution: how insect evidence helps solve crimes. Harvard University Press, Cambridge

Goff ML (2009) Early post-mortem changes and stages of decomposition in exposed cadavers. Exp Appl Acarol 49. doi:10.1007/s10493-009-9284-9

Grassberger M, Frank C (2004) Initial study of arthropod succession on pig carrion in a central European urban habitat. J Med Entomol 41:511-523

Gunn A (2006) Essential forensic biology: animals, plants and microorganisms in legal investigations. Wiley, Chichester

Haskell NH, Hall RD, Cervenka VJ (1997) On the body: insect's life stage presence and their postmortem artefacts. In: Hagland WD, Sorg MH et al (eds) Forensic taphonomy-the post mortem fate of human remains. CRC Press, Boca Raton, pp 415-467

Horak B, Dutkiewicz J, Solarz K (1996) Microflora and acarofauna of bed dust from homes in Upper Silesia, Poland. Ann Allergy Asthma Immunol 76:41-50

Hughes AM (1976) The mites of stored food and houses. Her Majesty's Stationary Office, London

Hwang C, Turner BD (2005) Spatial and temporal variability of necrophagous Diptera from urban to rural areas. Med Vet Entomol 19:379-391

Kazumi T, Takaya I, Jyun-ichi $\mathrm{H}$ et al (1992) Occurrence of aquatic oribatid and astigmatid mites in swimming pools. Water Res 26:1549-1554

Klotzbach H, Krettek R, Bratzke H et al (2004) The history of forensic entomology in German-speaking countries. Forensic Sci Int 144:259-263

Mégnin P (1892) Les acariens parasites [Parasitic acarines]. Encyclopédie Scientifique des Aide-Mémoire, Paris 
Mégnin P (1894) La Faune des Cadavres. Application de l'Entomologie à la Médecine Légale [The fauna of corpses. Application of entomology to forensic medicine]. G. Masson and Gauthier-Villars et Fils, Paris

Merck M (2007) Veterinary forensics: animal cruelty investigations. Iowa State University Press, Ames

Nielsen BO, Mahler V, Rasmussen P (2000) An arthropod assembage and the ecological condition in a byre at the neolithic settlement of Weier, Switzerland. J Archaeol Sci 27:209-218

OConnor BM (2009) Astigmatid mites (Acari: Sarcoptiformes) of forensic interest. Exp Appl Acarol 49. doi:10.1007/s10493-009-9270-2

Perotti MA (2009) Mégnin re-analysed: the case of the newborn baby girl, Paris, 1878. Exp Appl Acarol 49. doi:10.1007/s10493-009-9279-6

Perotti MA, Braig HR (2009) Phoretic mites associated with animal and human decomposition. Exp Appl Acarol 49. doi:10.1007/s10493-009-9280-0

Perotti MA, Braig HR, Goff ML (2009) Phoretic mites and carcasses. In: Amendt J, Goff ML, Campobasso $\mathrm{CP}$ et al (eds) Current concepts in forensic entomology. Springer, Dordrecht

Proctor HC (2009) Can freshwater mites act as forensic tools? Exp Appl Acarol 49. doi:10.1007/s10493009-9273-z

Sachs JS (2001) Corpse: nature, forensics, and the struggle to pinpoint time of death (=time of death: nature, forensics and the search for death's stopwatch). Perseus Publishers, Cambridge

Schelvis J (1990) Mites (Acari) in archaeology. Neth Entomol Soc Exp Appl Entomol Sec Proc 1:90-95

Schelvis J (1994) Predatory mites (Acari, Gamasida) in excrements of 5 domestic animal species. Pedobiologia 38:72-80

Seniczak S, Norton RA, Wang HF (1998) The morphology of juvenile stages of moss mites of the family Trhypochthoniidae (Acari: Oribatida), and the taxonomic status of some genera and species. Zool Anz 237:85-95

Sinclair L, Merck M, Lockwood R (2006) Forensic investigation of animal cruelty: a guide for veterinary and law enforcement professionals. Humane Society Press, Gaithersburg

Solarz K (2009) Indoor mites and forensic acarology. Exp Appl Acarol 49. doi:10.1007/s10493-009-9292-9

Solhoy IW, Solhoy T (2000) The fossil oribatid mite fauna (Acari: Oribatida) in late-glacial and earlyHolocene sediments in Krakenes Lake, western Norway. J Paleolimnol 23:35-47

Treat AE (1975) Mites of moths and butterflies. Cornell University Press, Ithaca

Turner B (2009) Forensic entomology: a template for forensic acarology? Exp Appl Acarol 49. doi:10.1007/ s10493-009-9274-y

Van Bronswijk JEMH (1981) House dust biology for allergists, acarologists and mycologists. NIB, Zeist

Walter DE, Proctor HC (2001) Mites in Soil, an interactive key to mites and other soil microarthropods. ABRS identification series. CSIRO, Collingwood

Warner A, Bostrom S, Moller C et al (1999) Mite fauna in the home and sensitivity to house-dust and storage mites. Allergy 54:681-690 